\title{
LEARNING THE LIFE SKILL: CEAB Lifelong Learning Graduate AtTribute
}

\author{
Sadegh Babaii Kochekseraii and Libby Osgood \\ School of Sustainable Design Engineering, University of Prince Edward Island \\ sbabaii@upei.ca, eosgood@upei.ca
}

\begin{abstract}
The focus of this paper is to present a baseline to a proposed longevity project for enhanced introduction of lifelong learning skill to engineering students. Lifelong learning is one of the twelve graduate attributes identified and evaluated by CEAB in the accreditation process of Canadian engineering programs. ENGN 326: Materials, Mechanics and Manufacturing is a third year core course with a broad scope of topics Students' learning experience could be enriched if they adopt a proactive learning effort of setting weekly learning goals that could go beyond the set of topics given in the course syllabus. From their weekly submissions and their subsequent reflections, we tried to answer how realistic goals were set by the students and how much they were related to course materials. Comparisons to a similar study [1], presented in CEEA16 by the authors, have been made to show the effectiveness of SMART goal setting intervention to be given in an appropriate time before the first mid-term.
\end{abstract}

Keywords: CEAB graduate attributes, lifelong learning, SMART learning goals

\section{INTRODUCTION}

Lifelong learning is a key attribute for new and experienced engineers to excel in their future tasks and enhance their career outlook. Authors of this paper, coming from aerospace and automotive industries to academia, have a firsthand experience of the importance lifelong learning played in their professional development and those of their peers and colleagues. In lieu of this, it is their interest to further investigate how to make the Canadian Engineering Accreditation Board (CEAB) Lifelong Learning Attribute a lifelong learning skill learnt in the classroom.

Engineering graduates are expected to perform their assigned tasks right out of school without extensive additional training. To help graduates meet this expectation, $\mathrm{CEAB}$ has developed a set of key attributes expected of engineering students to have acquired at the time of their graduation. Not only attributes such as knowledge of engineering, use of tools, problem solving, teamwork and design - technical skills -, but also professional skills such as equity, ethics, professionalism and lifelong learning to just name a few. Professional skill development such as lifelong learning has always been taken as an implicit result of completing projects and design tasks in the degree program. The CEAB on the other hand insists that all attributes are explicitly introduced, developed, applied and assessed in the curriculum.

The School of Sustainable Design Engineering (UPEI Engineering) at University of Prince Edward Island is cutting edge in introducing hands on and practical engineering practice back to university engineering education. It is orientated around project based design, learning and professional practice courses through all four years of studies with emphasis on professional skill development (PSD), hands-on content and experiential learning elements. This new approach is presenting to the teachers a green field opportunity to develop new ways of introducing concepts such as equity, ethics, professionalism and lifelong learning proactively.

Working in industry and practicing professional engineers requires setting annual professional development goals and show evidence of achieving those career objectives. We argue that this practice in the industry is similar to the CEAB requirement for the lifelong learning skills. With no other engineering course known to us that proactively introduces, applies and then assesses lifelong learning habits and strategies, we reported in CEEA16 [1] our results of experimenting a new method using the focus area elective course ENGN 334 (2015): Introduction to Mechatronics given in Fall 2015 by the corresponding author. The intention was for the students learn and practice better goal setting skills. We encouraged the students to proactively participate in developing their own weekly learning goals based on the proposed study outline. A learning session (intervention) was given on how to write active, meaningful and achievable learning goals, just before the midterm assessment. 
We tried to answer the following questions.

1. Are students setting realistic goals?

2. How does the balance of short term and long term goals change over the semester?

3. How proactively are students connecting to course material as listed in the syllabus?

4. Do they ask for topics to be covered to ensure their goals are met?

While we could provide some analysis for the first two questions, answering all should require a longevity study and possibly a future field research to assess how useful they find their learning.

It is therefore the objective of this paper to present, compare and contrast the results of weekly goal setting practice in another third year class ENGN 326 (2016): Materials, Mechanics and Manufacturing also given by the corresponding author at UPEI. Eight students from a population of 16 agreed to use of their goals in an anonymous manner.

\section{BACKGROUND}

In 2008, the CEAB published a set of new requirements [2] in which included a list of graduate attributes specific to an outcome based accreditation criteria. Section 3.1 of this document lists 12 graduate attributes all students should have acquired upon completion of an accredited engineering program. The last in the list was lifelong learning skills.

The CEAB defines lifelong learning graduate attribute as "An ability to identify and to address their own educational needs in a changing world, sufficiently to maintain their competence and contribute to the advancement of knowledge" [2]. At UPEI Engineering, we further elaborated the definition to cover stages "Introduced" through "Developed" as follows:

1. Recognize the need for self-learning skills and reflection,

2. Compose reflections evaluating personal work performance,

3. Define personal, interpersonal and professional skills themselves,

4. Identify knowledge gaps and learning needs,

5. Practice improvement of personal, interpersonal and professional skills, and

6. Set personal self-learning goals

SMART goals are described in "The Power of SMART Goals" by O'Neill et.al. (2006)[4]. Tofade etal [5] in a study regarding Continued Professional Development (CDP) of $1^{\text {st }}$ year and $2^{\text {nd }}$ year pharmacy students concludes that "with focused online or live training, students are capable of incorporating principles of CPD by writing SMART learning objectives".

Students in ENGN 326 were encouraged to practice a goal writing process incorporating Bloom's Taxonomy of Educational Objectives [3].

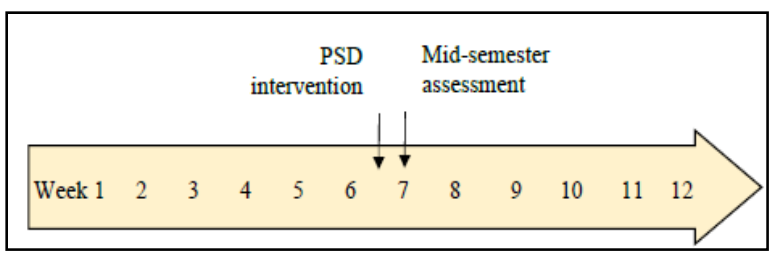

Fig.1. Timeline shows a pre-midterm intervention given around week 6 in ENGN 334 (2015). A pre-midterm PSD intervention was not given in ENGN 326 (2016).

\section{METHOD}

In the Fall 2016 semester, students in ENGN 326 were introduced to proactive learning goal-setting. Students completed twelve weekly assignments to set goals for their learning of the upcoming week and reflecting on their learning achievements from the previous week according to what they previously set the week before. In contrast to similar exercise carried out by the author in ENGN 334 (2015) class [1], there was no single intervention given between the weeks sixth and seventh of the term; rather there was continuous interaction via the Moodle online learning platform between the professor and each students to help them improve their goal setting skill. Figure 1 shows a time line representation of the above. After the end of the semester in 2017, permission was requested from the 16 student population of ENGN 326 to use their learning objective for the research-ethics board approved study.

This study is the quantitative analysis of the learning objectives from the twelve weekly submissions. The sample consists of eight third-year engineering students. To answer question one above, participants - referred to as S1 to S8 - were asked to identify and set a number of weekly learning goals. Each learning objective was given a quality score from 0 to 5 , with one point for each of the following SMART [4] criteria:

- Specific: A clearly defined, specific goal

- Measureable: Containing ways to access progress

- Attainable: Can be attained within set time frame using available resources

- Relevant: Being relevant to the targeted topic

- Time bound: Having a specific time frame to complete the goal. 
A simple evaluation rubric was used in which the score of a submitted learning goal was based on the presence of elements of SMART in the goal.

For example, a learning goal stating "I would like to learn what hardness and impact properties are and how they are calculated in the real world" scores 3 for the presence of S, M \& R elements (specific, measurable and relevant).

On the other hand, a learning goal stating "Learn about material design. The goal for this week will be to cover Statistical Significance of Material Properties as we did not have time to do so last week with the class cancellation, as well cover how strength and cold works and hardness and impact properties. This is a knowledge based learning goal. I will reach this goal by attending lectures as well as reading the appropriate chapters in the textbook" scores 5 for the presence of the five elements in SMART.

In addition to this simple rubric and approaching SMART evaluation more strictly, the authors decided to evaluate future learning goals according to the following strict rubric:

Table 1: Strict SMART evaluation rubric.

\begin{tabular}{|r|r|l|l|l|}
\hline $\mathbf{5}$ & $\mathbf{4}$ & $\mathbf{3}$ & $\mathbf{2}$ & $\mathbf{1}$ \\
\hline SMART & $\begin{array}{l}\text { "S, T", plus } \\
\text { two more }\end{array}$ & $\begin{array}{l}\text { "S, T", plus } \\
\text { one more }\end{array}$ & $\begin{array}{l}\text { only " S " } \\
\text { and/or "T" }\end{array}$ & $\begin{array}{l}\text { goals } \\
\text { submitted }\end{array}$ \\
\hline
\end{tabular}

Accordingly, the submitted goal above with simple score 3 will be scored 2 for having only $\mathrm{S}$. The goal that scored 5 will continue to score 5 . The results were averaged each week for each student and plotted against weeks one to twelve of the fall term 2015.

In this paper, we are proposing a methodology to answer question 3 quantitatively by evaluating the presence of $\mathrm{S} \& \mathrm{R}$ (specific and relevant) elements of SMART criteria as the submitted goal being course related vs not course related if one or both are missing. For example, the goal "Understanding the difference between design engineering and engineering design" scores course related or 1 ( $\mathrm{S} \& \mathrm{R}$ - specific and relevant). On the other hand, the goal "Try to encourage the class this week to try and learn more out of the material being presented, we need to regain the engineering power" scores SAT (specific, attainable and time bound) but assessed as not course related or 0 , being a learning objective in leadership and communication and not materials and mechanics.

\section{RESULTS AND DISCUSSIONS}

In ENGN 334 (2015) we observed the sample population of the class became SMART-er after receiving the PSD as Figure 2 clearly shows. And, to discuss is it better to promote longer term goals vs weekly goals?

\subsection{Realistic Learning Goals}

Figures 2 and 3 present the averaged SMART scores for classes ENGN 334 (2015) and ENGN 326 (2016). Figure 2 shows a significant improvement of the learning goals set by the students after the PSD intervention was given on week 6 by one of the authors. It appears to show a drop in the class averaged SMART scores in weeks prior to the intervention; possibly explained by students' confusion about the features of a good learning goal. A PSD intervention was not given to the students in ENGN 326 (2016), however weekly individual comments were provided to every student to improve their goals for the first part of the term up until week six. Figure 3 appears to show this gradual improvement in the quality of the learning goals set by the students but without the significant effect of a PSD given by a professor external to the course. The trend in figure 3 is positive and indicative to an eventually high class averaged score of about 4.5 either measured in a simple or a strict manner.

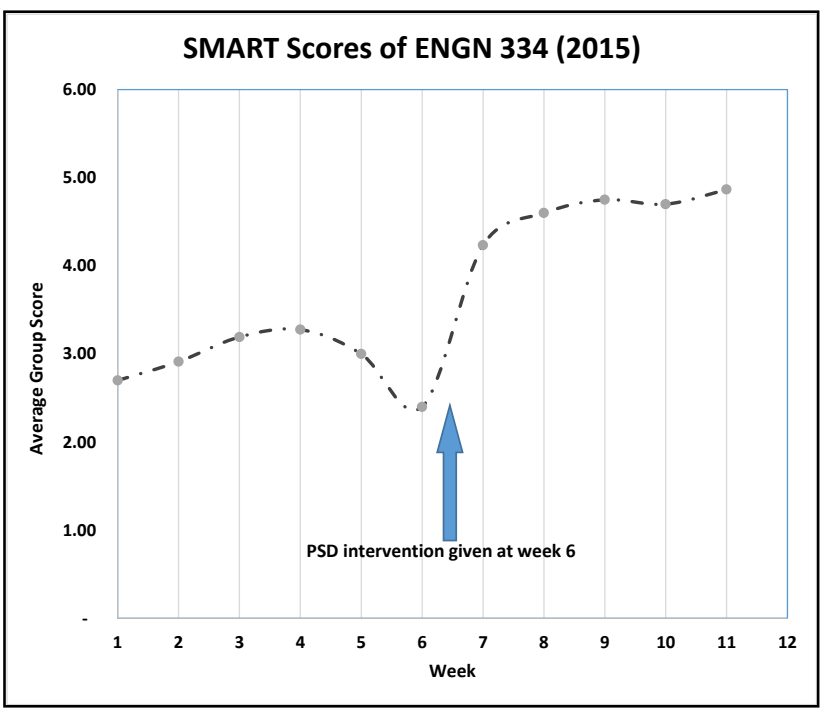

Fig.2. Averaged SMART scores of submitted learning for the sample population of 4 in ENGN 334 (2015).

Authors agree that the results from the first two years of this experiment indicates that an explicit intervention in form of a PSD should be delivered by an invited external professor to the classroom to bring significant and lasting improvement to the goals. Authors also agree that the proposed PSD intervention should be early in the academic term but no earlier than the third week and certainly before the middle of the academic term. Figure 4 shows this very clearly on which basis authors are proposing to continue with this activity in a longevity study over the next three to five years in a course for second or third year students delivered by the corresponding author. 


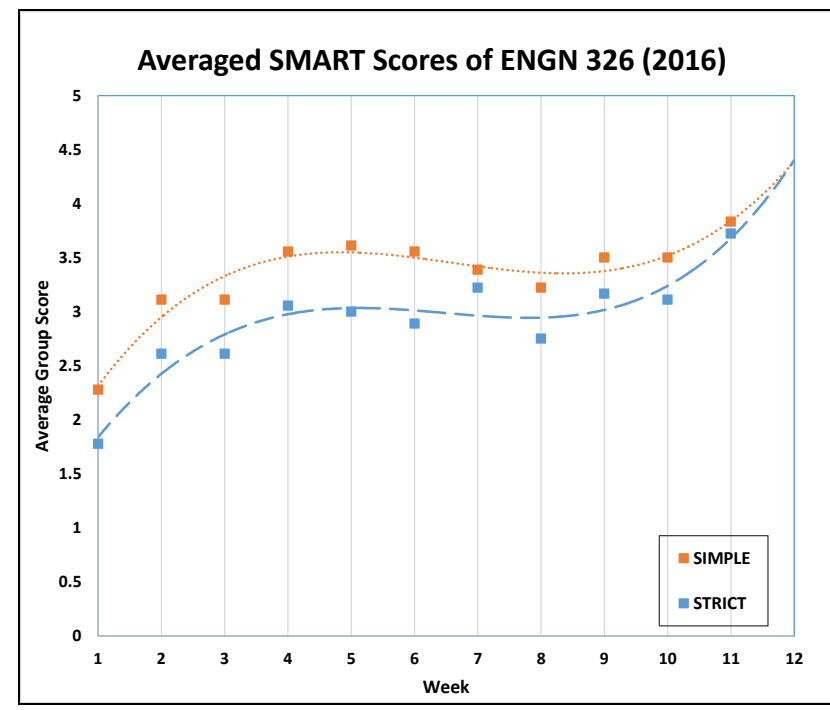

Fig.3. Averaged SMART scores of submitted learning goals for the sample population of 8 in ENGN 326 (2016). Data in Orange present a more relaxed simple approach to evaluating the goals but the blue data show a stricter evaluation rubric of the same submitted goals according to table 1 above.

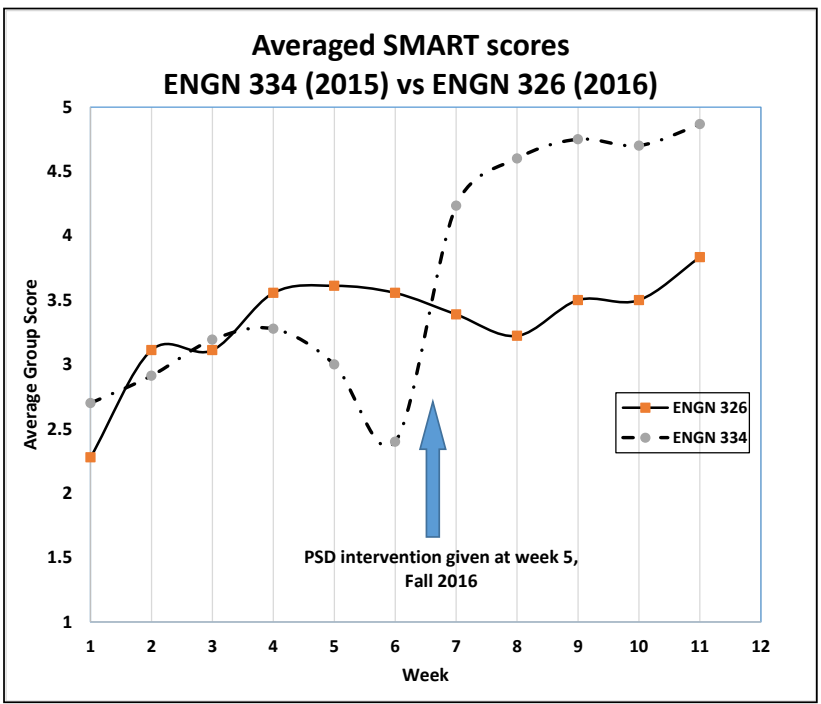

Fig.4. Averaged SMART scores for ENGN 334 (2015) vs ENGN 326 (2016). The effect of explicit PSD intervention is clearly observed vs the constant individual comments by professor via the Moodle learning platform.

\subsection{Connecting to Course Materials}

In section 4.1, authors presumed the necessity of SMART goals to be both Specific and Time Bound as the minimum requirement to be considered realistic. In this section, we would like to propose that they should be as a minimum both Specific and Relevant to be considered as connected to the course material.

All learning goal submissions were reviewed and were given a score of 1 or 0 corresponding to as being course material related or not. For each participating students S1 to S8, we scored the percentage they submitted out of expected 36 goals (of 3 learning goals for each of 12 weeks). We then summed up their course related score by summing the ones. Looking at figure 5, a number of scenarios are possible. Student S1 only submitted $69 \%$ of the 36 expected learning goals for the term but $100 \%$ of them were course related. In contrast, student S2 submitted $100 \%$ of the expected learning goals but only $72 \%$ were considered as course related. Finally, student S5 diligently submitted all the expected learning goals and all of them were considered relevant. Most interestingly, student S8, whom dutifully submitted $100 \%$ of the expected learning goals, had only a low $47 \%$ of them identified as course material related.

It now appears to the authors that drawing a connection between course material connectivity score and student overall performance could bring about interesting new information. For example, how students S2, S5 and S8 fared in the course at the end of the term. A future iteration of this study will include final grade comparison.

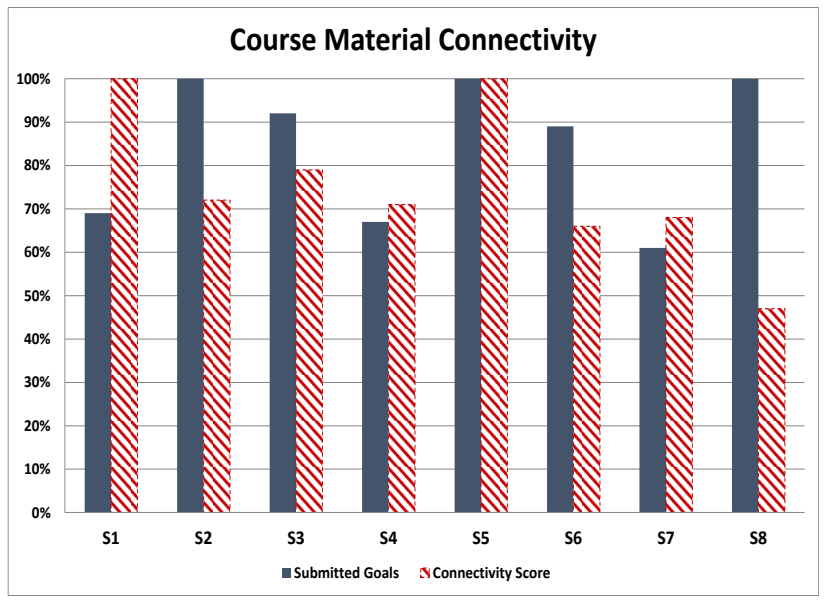

Fig.5. \% of submitted learning goals by each student A to $\mathrm{H}$, and course material connectivity score for each in ENGN 326 (2016)

\section{CONCLUSIONS AND FUTURE WORK}

We were pleased to have the opportunity to continue with the innovative project we started last year and reported in CEEA16. At the end of two years of studies we conclude: 
- Lifelong learning skill and realistic goal setting has to be purposefully taught to the students as suggested by this two year study.

- Realistic goal setting skill should be introduced in a single and explicit PSD early in the term as possible after week 2.

- Explicit reference to Bloom's taxonomy for goal setting and SMART effective goals is important to provide students with some terms of reference in their future professional life.

- Course material connectivity should be actively encouraged to the students as they are setting their weekly goals.

- Course material connectivity should not be interpreted and be used in a way to limit the scope of learning of students to the list of topics given in the syllabus by the professor.

As we are not aware of other similar studies in the literature by experts in engineering education and pedagogy; we are open to receive constructive comments, discussions from peers and colleagues in Canadian education and Canadian engineering education, in particular regarding our approach to the subject matter of introducing lifelong learning skill and future improvements to our analysis and discussion of results in this particular topic.

As the next step, we propose a 3 year longevity study in which either a second year or a third year engineering course will be asked to submit weekly learning goals and reflections. The class will be educated in the first week by the professor in better (ie. SMART-er) goal setting that will be followed by a PSD intervention in week three or four as mentioned in 4.1. The strict SMART evaluation will be adopted to emphasize on goals being both specific and time bound and to make sure students can achieve their goals in their set time frame. They will be encouraged to set a mix of short term time bounded and long term time bounded learning goals for better management of their learning achievements. We will try to compare goal setting performance of students to their relative performance in the course as pointed in section 4.2.

\section{Acknowledgements}

Authors would like to thank all the students in ENGN 326 (2016) and ENGN 334 (2016) whom effortlessly submitted their weekly goals irrespective of their participation in this study. There were valuable learnings in reading them and commenting on weekly basis.

Authors would like to sincerely wish all the best of success for the students in ENGN 334 (2015) class whom are proudly our first engineering graduates from the new
Sustainable Design Engineering degree program at the University of Prince Edward Island.

\section{References}

[1] Sadegh Babaii Kochekseraii, and Libby Osgood, "Lifelong learning: a skill needed today for the engineers of the future", Paper 53 in Proc.CEEA Canadian Engineering Education Association Conf., CEEC16, (Halifax, NS; 19-22 June 2016), 5 pp, 2016.

[2] Canadian Engineering Accreditation Board , 2014 Accreditation Criteria and Procedures / Bureau canadien d'agrément des programmes de génie: Normes et procédures d'agrément. Ottawa, ON: Engineers Canada / Ingénieurs Canada, 2014. 116pp. \{ISSN 1708-8054\}. Available from https://www.engineerscanada.ca/sites/default/files/2014_accr editation_criteria_and_procedures_v06.pdf

[3] Benjamin S. Bloom, M. D. Engelhart, E. J. Furst, W. H. Hill, and David R. Krathwohl, Taxonomy of Educational Objectives: The classification of educational goals. Handbook I: Cognitive domain. New York, NY: David McKay Company, 1956.

[4] Jan O'Niell, Anne Conzemius, The Power of SMART Goals: Using Goals to Improve Student Learning. Bloomington, IN: Solution Tree Press, 2006, 194pp. \{ISBN 978-1932127-87-4\}

[5] Toyin Tofade, Anand Khandoobhai, and Kim Leadon, "Instructional design and assessment: Use of SMART learning objectives to introduce continuing professional development into the pharmacy curriculum, "American Journal of Pharmaceutical Education, vol. 76, no. 4, Article 68, 2012. 